\title{
Optimization of Casting Process Parameters for Synthesis of Al-Nb-B Master Alloy
}

\author{
SHRISTY JHA,${ }^{1}$ ANIMESH MANDAL,${ }^{1}$ and PRAKASH SRIRANGAM ${ }^{2,3}$ \\ 1.-School of Minerals, Metallurgical and Materials Engineering, Indian Institute of Technology \\ Bhubaneswar, Argul, Bhubaneswar 752050, India. 2.-WMG, University of Warwick, Coventry \\ CV4 7AL, UK. 3.-e-mail: p.srirangam@warwick.ac.uk
}

\begin{abstract}
Al-Nb-B master alloys were synthesized using commercial pure aluminum, niobium, and $\mathrm{KBF}_{4}$ salts. Two different sources of $\mathrm{Nb}$ (pure $\mathrm{Nb}$ powder and $\mathrm{Al}-$ $60 \% \mathrm{Nb}$ powder) were used to prepare the master alloy. Casting process parameters such as reaction time and melt stir time interval were varied to enhance the formation of in situ intermetallic particles in the master alloys. The size, shape and distribution of intermetallic particles in these master alloys were studied using microscopy techniques. The results show that the $\mathrm{Al}-5 \mathrm{Nb}-1 \mathrm{~B}$ master alloy prepared with $\mathrm{Al}-60 \% \mathrm{Nb}$ powders has a uniform distribution of intermetallic particles as compared to the master alloy prepared with pure $\mathrm{Nb}$ powders. Increase in boron content from 1 wt.\% to 2 wt.\% in the master alloys resulted in a higher fraction of intermetallic particles. Among all the master alloys synthesized, Al-5Nb-2B was observed to have the highest number of well-distributed intermetallic particles which could act as potential grain refiners of aluminum alloys.
\end{abstract}

\section{INTRODUCTION}

Grain refinement is a prominent way of improving the mechanical properties of cast aluminum alloys for automotive and aerospace applications. ${ }^{1}$ Grain refinement of aluminum alloys is usually carried out by various methods, such as inoculation, rapid cooling and the application of external fields, such as ultra-sonication, electromagnetic stirring, etc. ${ }^{2}$ Among these grain refining methods, inoculation of the melt, which includes the addition of particles by in situ reactions, is a very common method in aluminum alloys. These particles act as heterogeneous nucleation sites for the grain refinement of alloys. ${ }^{3} \mathrm{In} \mathrm{Al}-\mathrm{Cu}$ alloys, titanium along with boron or carbon were found to be very effective in the refinement of primary $\mathrm{Al}$ grains. ${ }^{4}$ The fluxassisted synthesis route, which involves the addition of $\mathrm{KBF}_{4}$ and $\mathrm{K}_{2} \mathrm{TiF}_{6}$ salts to molten aluminum, is considered to be the most preferred route to prepare Al-Ti-B master alloys. In flux-assisted synthesis, the particles are formed by an exothermic reaction of salts which results in enhanced wettability and better microstructural stability of the master alloy. ${ }^{5}$ Addition of $0.01 \mathrm{wt} . \% \mathrm{Ti}$ in the form of a master alloy to $\mathrm{Al}-\mathrm{Cu}$ melt results in the formation of $\mathrm{TiB}_{2}$ and $\mathrm{Al}_{3} \mathrm{Ti}$ particles, which aid in grain refinement of the alloy. ${ }^{6,7}$ However, $\mathrm{TiB}_{2}$ and $\mathrm{Al}_{3} \mathrm{Ti}$ particles are found to be ineffective in grain refining of aluminum alloys that contain high amount of $\mathrm{Si}, \mathrm{Li}, \mathrm{Cr}$ and $\mathrm{Zr} .{ }^{8-11}$ Recent studies have reported that the niobium addition which forms $\mathrm{Al}_{3} \mathrm{Nb}$ particles in the melt is found to be an effective grain refiner of Al-Si alloys. ${ }^{12-15}$ Further, it has been observed that the addition of $\mathrm{Nb}$ along with $\mathrm{B}$ enhances the grain refinement of $\mathrm{Al}-\mathrm{Si}$ alloys as compared to the refinement occurring with only $\mathrm{Nb}$ or boron additions. This enhanced grain refinement was attributed to the similarities between the $\mathrm{Al}-\mathrm{Nb}-\mathrm{B}$ and $\mathrm{Al}-\mathrm{Ti}-\mathrm{B}$ systems. It was reported that the particles formed in Al-Nb-B master alloys are $\mathrm{NbB}_{2}$ and $\mathrm{Al}_{3} \mathrm{Nb}$, and that they are isostructural with $\mathrm{TiB}_{2}$ and $\mathrm{Al}_{3} \mathrm{Ti}$ in Al-Ti-B alloys. Also, the lattice mismatch parameters of $\mathrm{NbB}_{2}$ and $\mathrm{Al}_{3} \mathrm{Nb}$ with the $\mathrm{Al}$ matrix is similar to that of $\mathrm{TiB}_{2}$ and $\mathrm{Al}_{3} \mathrm{Ti}$ with the $\mathrm{Al}$ matrix. However, the main advantage of Nb-based particles over Ti-based particles is that $\mathrm{Nb}$ does not form any intermetallic compounds with $\mathrm{Si}$ in $\mathrm{Al}-\mathrm{Si}$ alloys. Hence, the stability of $\mathrm{Nb}$-based intermetallic compounds is proved to be effective even in the presence of higher amounts of $\mathrm{Si}$ in $\mathrm{Al}-\mathrm{Si}$ alloys. Several studies have 
been reported on the grain-refining efficiency of Al$\mathrm{xNb}-\mathrm{yB}$ master alloys on grain refinement of commercial Al-Si alloys. ${ }^{16-20}$ Although research studies have been carried out on the grain refinement of Al$\mathrm{Si}$ alloys using Al-Nb-B master alloys, very little emphasis has been laid on optimizing the casting process parameters during the synthesis of $\mathrm{Al}-\mathrm{Nb}-\mathrm{B}$ master alloys meant for grain refinement of $\mathrm{Al}-\mathrm{Si}$ alloys. The aim of this publication is to study the effect of casting process parameters such as sources of $\mathrm{Nb}$, reaction times, effects of stirring on synthesis and microstructures of $\mathrm{Al}-\mathrm{Nb}-\mathrm{B}$ master alloys.

\section{EXPERIMENTAL DETAILS}

\section{Synthesis of Al-Nb-B Master Alloys}

The raw materials used for making the master alloys include commercially pure $\mathrm{Al}$ (CP $\mathrm{Al}$ ) (> 99.8\% purity), pure niobium powders $(99.99 \%$ pure, 200 mesh size; HiMedia, India), Al-60Nb powder (average size $\sim 400 \mu \mathrm{m}$; Baoji Rui Hong Metal Materials, China) and $\mathrm{KBF}_{4}$ salts $(98 \%$ purity; Madras Fluorine, India). Figure 1 represents the SEM images of the as-received pure $\mathrm{Nb}$ powders (Fig. 1a) and Al-60\% Nb powders (Fig. 1b), which are two different $\mathrm{Nb}$ sources.

Figure $1 \mathrm{c}$ is a schematic of the experimental setup. Al-Nb-B master alloys with varied $\mathrm{Nb}: \mathrm{B}$ ratios were synthesized by adding $\mathrm{Al}-60 \% \mathrm{Nb}$ or pure $\mathrm{Nb}$ and $\mathrm{KBF}_{4}$ into the $\mathrm{Al}$ melt together. First, an $\mathrm{Al}-5 \mathrm{Nb}-1 \mathrm{~B}$ master alloy was prepared by adding $\mathrm{Al}-60 \% \mathrm{Nb}$ powders to molten aluminum in a graphite crucible. The amount of total melt in all the cases was $300 \mathrm{~g}$. The melt was kept at $800^{\circ} \mathrm{C}$ for 30 min for homogenization, followed by $\mathrm{KBF}_{4}$ salts being added to the melt. The melt was stirred at regular intervals prior to casting in a split-type graphite mold. To study the effect of reaction time, three reaction times were selected: $1 \mathrm{~h} 30 \mathrm{~min}, 2 \mathrm{~h}$ $15 \mathrm{~min}$, and $2 \mathrm{~h} 45 \mathrm{~min}$. In another set of experiments, to check the effect of sequence of addition of raw materials, both sources of $\mathrm{Nb}$ and $\mathrm{KBF}_{4}$ were mixed together and then added to the melt, rather than adding them separately as in the previous case. As the received powders and salts were preheated to $200^{\circ} \mathrm{C}$ prior to adding to the melt. Thereafter, the effect of stirring of the melt on the the synthesis of master alloys was studied. For comparison, one of the melts was unstirred after the addition of $\mathrm{Nb}$ and $\mathrm{KBF}_{4}$ salts, while the other melt was stirred every $15 \mathrm{~min}$.

Also, experiments were carried out to synthesize master alloys of the same composition using different sources of $\mathrm{Nb}$, i.e., pure $\mathrm{Nb}$ powder and $\mathrm{Al}-60 \mathrm{Nb}$ powder. For the master alloy preparation, molten $\mathrm{Al}$ was homogenized for $2 \mathrm{~h}$ at $800^{\circ} \mathrm{C}$ and then a pre-


Fig. 1. FESEM micrographs of as-received (a) pure Nb powders, (b) Al-60Nb master alloy powders. (c) Experimental setup for the synthesis of Al-Nb-B mater alloy. 
heated mixture of $\mathrm{Nb}$ powders $+\mathrm{KBF}_{4}$ salt and $\mathrm{Al}$ $60 \mathrm{Nb}$ powders $+\mathrm{KBF}_{4}$ salt was added. The $\mathrm{Nb}$ or $\mathrm{Al}-60 \mathrm{Nb}$ powders were wrapped in aluminum foil prior to addition to the melt. The wrapped powders were carefully plunged inside the melt and then stirred. This was done to prevent oxidation of the $\mathrm{Nb}$ particles. After holding at $800^{\circ} \mathrm{C}$ for $1 \mathrm{~h}$, the temperature was raised to $850^{\circ} \mathrm{C}$ and held for 30 min for better dissolution of pure $\mathrm{Nb}$ and $\mathrm{Nb}$ containing particles in Al-60Nb alloy. Then, the temperature was brought down to $800^{\circ} \mathrm{C}$ and held for another $30 \mathrm{~min}$ to minimize the loss of $\mathrm{B}$ in the form of $\mathrm{BF}_{3}$ gas. Thus, the total holding time was $2 \mathrm{~h}$. Finally, dross was removed, and the melts were cast into graphite split-type molds. In the final set of experiments, boron content in the master alloy was varied from 1 wt.\% to 3 wt.\%, keeping the $\mathrm{Nb}$ content fixed at 5 wt.\%. Dissolution of KBF4 is ensured by stirring the melt at intervals of $15 \mathrm{~min}$. The low melting point of the salt $\left(530^{\circ} \mathrm{C}\right)$ and high reactivity of the salt with molten aluminum ensures that it does not remain unreacted in the the liquid aluminum at the reaction temperature of $800^{\circ} \mathrm{C}$. Table I represents the parameters used in the synthesis of different Al-Nb-B master alloys.

\section{Optical and SEM Microscopy}

The cylindrical castings were sectioned at $2 \mathrm{~cm}$ from the bottom to prepare samples for metallography studies using standard metallographic techniques. The samples were etched with Keller's reagent for $30 \mathrm{~s}$ to study the particles in the microstructure. The alloys were examined under an optical microscope (NIKON ECLIPSE LV150 N) and FESEM [Carl Zeiss SMT instrument coupled with energy dispersive $\mathrm{x}$-ray spectrometer (EDS)].

\section{RESULTS AND DISCUSSION}

\section{Optimisation of Reaction Time for the Synthesis of Al-Nb-B Master Alloy}

Experiments were carried out for different total reaction times (defined as the time from the addition of $\mathrm{KBF}_{4}$ salt and/or Al-60Nb powder to the melt to pouring of the master alloy into the molds) to ensure complete formation of particles by the reaction of $\mathrm{KBF}_{4}$ salt and $\mathrm{Al}-60 \mathrm{Nb}$ powder in molten aluminum. The exothermic reaction between the $\mathrm{KBF}_{4}$ salts and the melt results in proper dissolution of $\mathrm{Nb}$ and the formation of compounds. ${ }^{21}$

Figures 2 represents FESEM micrographs of the Al-Nb-B master alloy for different reaction times. ( $1 \mathrm{~h} 30 \mathrm{~min}, 2 \mathrm{~h} 15 \mathrm{~min}$, and $2 \mathrm{~h} 45 \mathrm{~min}$, respectively). It is evident from the figure that the particles were formed in the master alloys for all reaction times; however, the particles were also found to be agglomerated. The agglomeration of boride particles could be due to the flux-generated reaction of $\mathrm{KBF}_{4}$ with the $\mathrm{Al}$ matrix and the engulfment of the KF-AlF ${ }_{3}$ salts. ${ }^{22}$ Also, as shown in Fig. 2, the longer the reaction time, the higher the chances for agglomeration formation which is expected, as particles have more time to react and agglomerate to reduce surface energy. ${ }^{23}$ Besides agglomeration, particle settling is also favored due to the high density of the in situ particles formed during the reaction. For example, particles such as $\mathrm{Al}_{3} \mathrm{Nb}$ and $\mathrm{NbB}_{2}$ (whose probability of forming is high in Al-Nb-B master alloys) have densities of $4.54 \mathrm{~g} / \mathrm{ml}$ and $6.98 \mathrm{~g} / \mathrm{ml}$, respectively, as compared to $\sim 2.3 \mathrm{~g} / \mathrm{ml}$ of molten aluminum at $800^{\circ} \mathrm{C} .{ }^{16}$ Hence, the melt should be held for less than or equal to $2 \mathrm{~h}$ after the addition of the powders, with stirring at regular intervals to lessen the tendency to the agglomeration and settling of particles.

Table I. Parameters used for synthesis of Al-Nb-B master alloys

\begin{tabular}{|c|c|c|c|c|c|}
\hline $\begin{array}{l}\text { Sl. } \\
\text { nos. }\end{array}$ & Objective & Composition & $\begin{array}{c}\text { Raw } \\
\text { materials }\end{array}$ & $\begin{array}{l}\text { Sequence of } \\
\text { addition }\end{array}$ & Procedure \\
\hline 1 & $\begin{array}{l}\text { Optimization of holding } \\
\text { time to dissolve } \mathrm{Nb} \text { and } \mathrm{B}\end{array}$ & $\mathrm{Al}-5 \mathrm{Nb}-1 \mathrm{~B}$ & $\begin{array}{l}\text { CPAl, } \mathrm{Al}-60 \mathrm{Nb} \\
\text { powder, } \mathrm{KBF}_{4}\end{array}$ & $\begin{array}{c}\mathrm{Al}-60 \mathrm{Nb}+ \\
\mathrm{KBF}_{4}\end{array}$ & $\begin{array}{c}\text { Pouring done at } 3 \text { different time } \\
\text { intervals }\end{array}$ \\
\hline 2 & $\begin{array}{l}\text { Optimization of stirring } \\
\text { interval and mixing the } \\
\text { raw materials before } \\
\text { addition }\end{array}$ & $\mathrm{Al}-5 \mathrm{Nb}-1 \mathrm{~B}$ & $\begin{array}{l}\mathrm{CPAl}, \mathrm{Al}-60 \mathrm{Nb} \\
\text { powder, } \mathrm{KBF}_{4}\end{array}$ & $\begin{array}{c}\mathrm{Al}-60 \mathrm{Nb}+ \\
\mathrm{KBF}_{4}\end{array}$ & $\begin{array}{l}\mathrm{Al}-60 \mathrm{Nb} \text { and } \mathrm{KBF}_{4} \text { pre-mixed. In the } \\
\text { first case, regular stirring and in the } \\
\text { the second, no stirring }\end{array}$ \\
\hline 3 & $\begin{array}{l}\text { To check the effect of } \mathrm{Nb} \\
\text { source for synthesizing } \\
\text { master alloy }\end{array}$ & $\mathrm{Al}-5 \mathrm{Nb}-1 \mathrm{~B}$ & $\begin{array}{l}\text { CPAl, Al-60Nb } \\
\text { powder, Pure } \\
\text { Nb powder, } \\
\mathrm{KBF}_{4}\end{array}$ & $\underset{\mathrm{KBF}_{4}}{\text { Pure } \mathrm{Nb}}+$ & $\begin{array}{c}\text { In the the first case, pure } \mathrm{Nb} \text { and } \\
\text { salt mixture was added, and in the } \\
\text { second casem Al-60Nb and salt mix- } \\
\text { ture }\end{array}$ \\
\hline 4 & $\begin{array}{l}\text { To check the effect of } \\
\text { increasing B content on } \\
\text { particle formation }\end{array}$ & $\begin{array}{l}\mathrm{Al}-5 \mathrm{Nb}-2 \mathrm{~B} \\
\mathrm{Al}-5 \mathrm{Nb}-3 \mathrm{~B}\end{array}$ & $\begin{array}{l}\mathrm{CPAl}, \mathrm{Al}-60 \mathrm{Nb} \\
\text { powder, } \mathrm{KBF}_{4}\end{array}$ & $\begin{array}{l}\mathrm{Al}-60 \mathrm{Nb}+ \\
\mathrm{KBF}_{4} \\
\mathrm{Al}-60 \mathrm{Nb}+ \\
\mathrm{KBF}_{4}\end{array}$ & $\begin{array}{c}\text { Amount of } \mathrm{KBF}_{4} \text { salts increased } \\
\text { accordingly }\end{array}$ \\
\hline
\end{tabular}



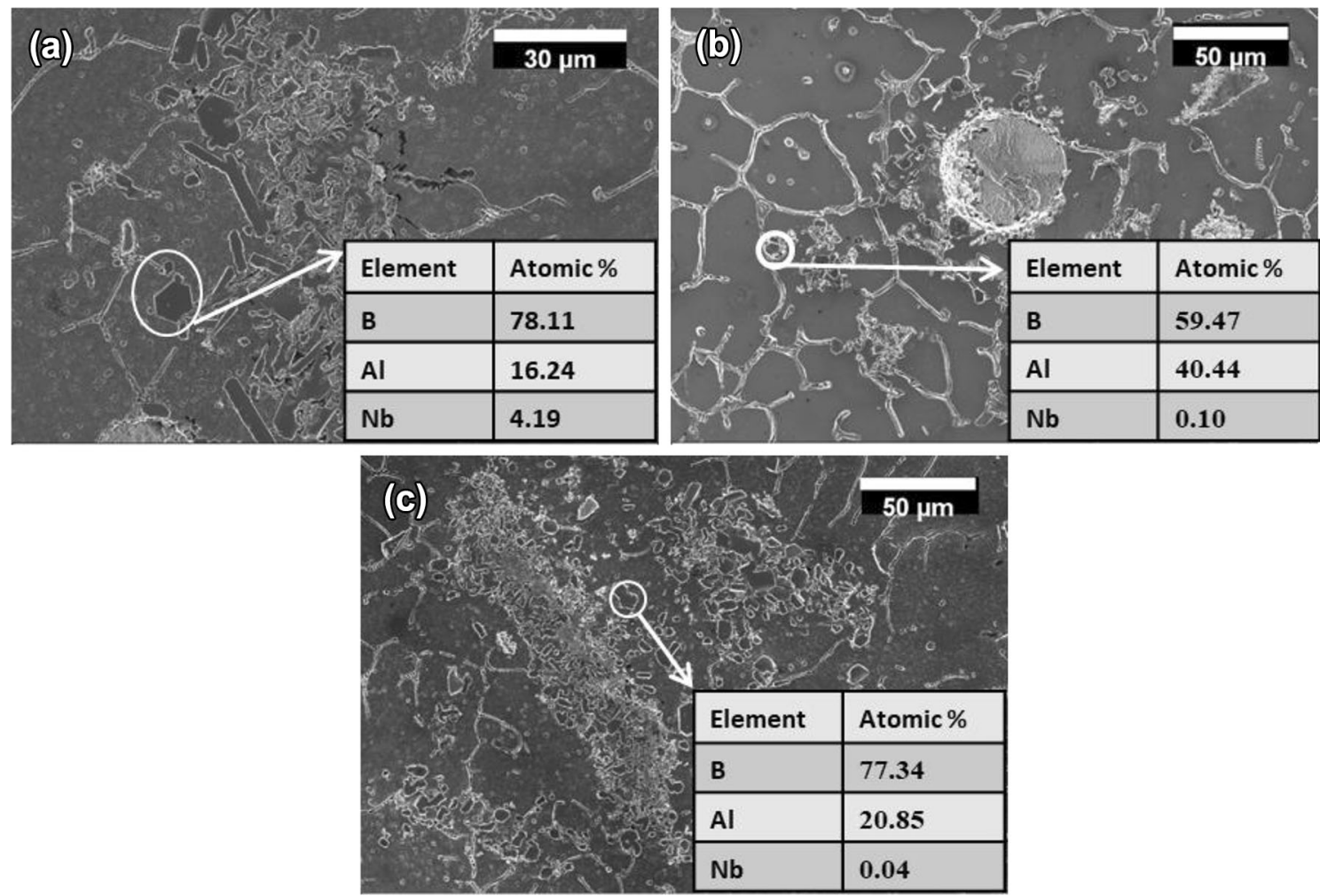

Fig. 2. FESEM micrographs and EDS analysis of the encircled particles after different reaction times: (a) $1 \mathrm{~h} 30 \mathrm{~min}$, (b) $2 \mathrm{~h} 15 \mathrm{~min}$, (c) $2 \mathrm{~h}$ $45 \mathrm{~min}$.

\section{Effect of Stirring and Addition Sequence of $\mathrm{KBF}_{4}$ Salt and Al-60Nb Powders on Al-Nb-B Master Alloy}

Figure 3 represents the SEM images of particles formed in the Al-Nb-B master alloy for stirred and unstirred melts. Figure $3 \mathrm{a}$ and $\mathrm{b}$ represents the effect of no stirring on particle formation, while Fig. $3 \mathrm{c}$ and $\mathrm{d}$ represent the particles formed in the stirred condition. This stirring study was undertaken because, in one of the cases, it was reported that stirring disturbs the layer of reacted salts and the aluminum is readily oxidized on the top of the melt. As a result, the chance of entrainment of residue salts in the melt increases, which promoting agglomeration. ${ }^{24}$ Thus, with the hope of reducing agglomeration, these sets of experiments were undertaken. However, in the present case, the melt which was not stirred at regular intervals, has a few coarse unreacted particles containing $\mathrm{Nb}$ and some unreacted salts, as supported by the $\mathrm{K}$ peaks shown in EDX on the particles, in Fig. 3a, $b$ and e. Stirring at regular intervals resulted in distinct, betterdistributed and finer particles with very few or almost no unreacted salts, as represented by Fig. 3c, $\mathrm{d}$ and $\mathrm{f}$. Thus, stirring is essential for the formation and uniform distribution of particles. This has also been substantiated in earlier reports. ${ }^{20}$

Also in the above cases (stirring and non-stirring), $\mathrm{Al}-60 \mathrm{Nb}$ powders and $\mathrm{KBF}_{4}$ salt were mixed before addition into the melt, unlike the previous cases
("Optimisation of reaction time for synthesis of AlNb-B master alloy" section) where they were added separately. It was observed that a higher fraction of particles formed when $\mathrm{KBF}_{4}$ salt and $\mathrm{Al}-60 \mathrm{Nb}$ powders are pre-mixed and added to the melt. This could be due to higher dissolution rate of particles like $\mathrm{Nb}_{2} \mathrm{Al}\left(1940^{\circ} \mathrm{C}\right)$ and $\mathrm{NbAl}_{3}\left(1680^{\circ} \mathrm{C}\right)$ present in the $\mathrm{Al}-60 \mathrm{Nb}$ alloy in the melt (Al-Nb binary phase diagram represented in Fig. 4f). This higher dissolution could be because of high amounts of energy released during the exothermic reaction of $\mathrm{KBF}_{4}$ salts with the aluminum, ${ }^{16}$ which leads to sudden increases in temperature of the melt, ultimately enhancing the reaction kinetics in the melt.Iin the cases where $\mathrm{KBF}_{4}$ salts were added 30 min after the addition of $\mathrm{Al}-60 \mathrm{Nb}$, dissolution of $\mathrm{Al}-60 \mathrm{Nb}$ would have been slower because of the initial lack of energy.

\section{Comparison of the Master Alloys Prepared with Al-60Nb and Pure Nb Powders}

Two master alloys of composition, each Al-5Nb$1 \mathrm{~B}$, were prepared using different sources of $\mathrm{Nb}$. The first master alloy (MA1) was prepared using pure $\mathrm{Nb}$ powder and $\mathrm{KBF}_{4}$ salt, and the the second master alloy (MA2) was prepared using $\mathrm{Al}-60 \mathrm{Nb}$ powder and $\mathrm{KBF}_{4}$ salt.

Figure 4 represents optical micrographs and SEM images of particles in the the Al-5Nb-1B alloy prepared with different sources of $\mathrm{Nb}$. Optical 

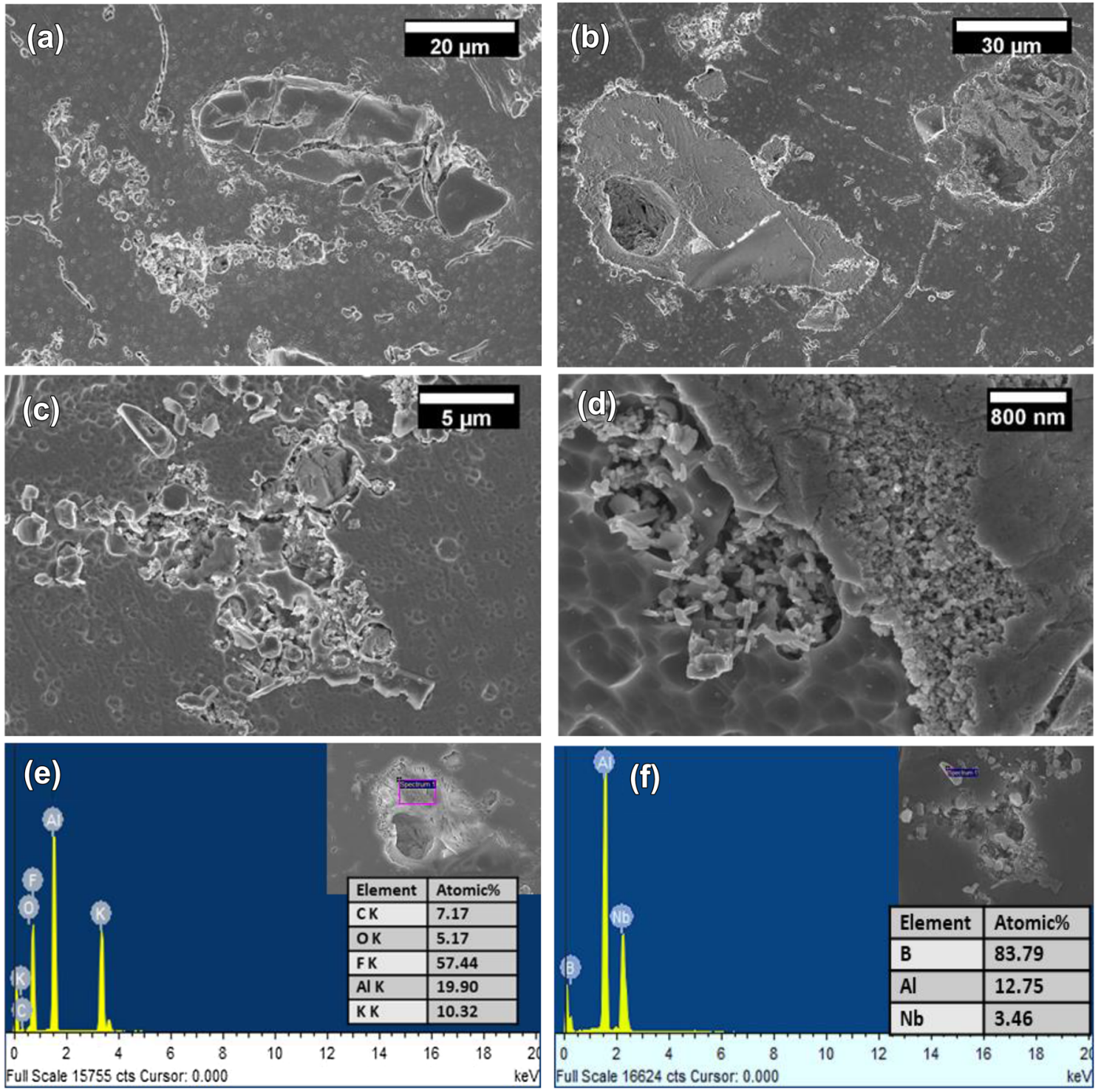

Fig. 3. FESEM micrographs of the particles in melt with (a, b) no stirring, (c, d) stirring every 15 min, (e) EDX on the region of the unstirred sample (showing traces of salt), and (f) EDX on particles formed in the case of the stirred sample.

microstructures in Fig. $4 \mathrm{a}$ and $\mathrm{b}$ shows the distribution of particle agglomerates throughout the sample. As shown in Fig. $4 \mathrm{c}$ and $\mathrm{d}$, clusters of coarse particles were observed in the Al-5Nb-1B master alloy prepared with $\mathrm{KBF}_{4}$ salts and pure $\mathrm{Nb}$ powders, while, on the other hand, small clusters of fine particles were observed in the the Al-5Nb-1B master alloy prepared with $\mathrm{KBF}_{4}$ salt and $\mathrm{Al}-60 \mathrm{Nb}$ powder, as shown in Fig. $4 \mathrm{e}$ and f. Also, more faceted particles were formed in the latter master alloy.

Figure $4 \mathrm{~g}$ shows the size distribution of the particles, as in Fig. 4a-d in both the master alloys. For this calculation, the feret diameters of a number of particles were measured from different regions in the microstructure using an image analysis software (ImageJ). The master alloy prepared with Al$60 \mathrm{Nb}$ powders have comparatively finer particles which were higher in number as compared to the master alloy prepared with pure $\mathrm{Nb}$. The average size of clusters is found to be small in the master alloy prepared with $\mathrm{Al}-60 \mathrm{Nb}$ powders compared to the master alloy prepared with pure $\mathrm{Nb}$ powders. In terms of particle formation, the fine size intermetallics with a higher fraction of particles were observed in the alloy synthesized with $\mathrm{Al}-60 \mathrm{Nb}$ compared to pure $\mathrm{Nb}$ powders. Also, the shape of the particles was found to be of faceted morphology in the alloy synthesised with $\mathrm{Al}-60 \mathrm{Nb}$ powders. The above-mentioned characteristics are important, because such particles facilitate better refining, as they promote better heterogeneous nucleation. ${ }^{1}$ There are two conjectures for the reason behind the master alloy made with $\mathrm{Al}-60 \mathrm{Nb}$ having a higher volume fraction of particles. First, the liquidus temperature of the $\mathrm{Al}-60 \mathrm{Nb}$ alloy $\left(1680^{\circ} \mathrm{C}\right)$ is 

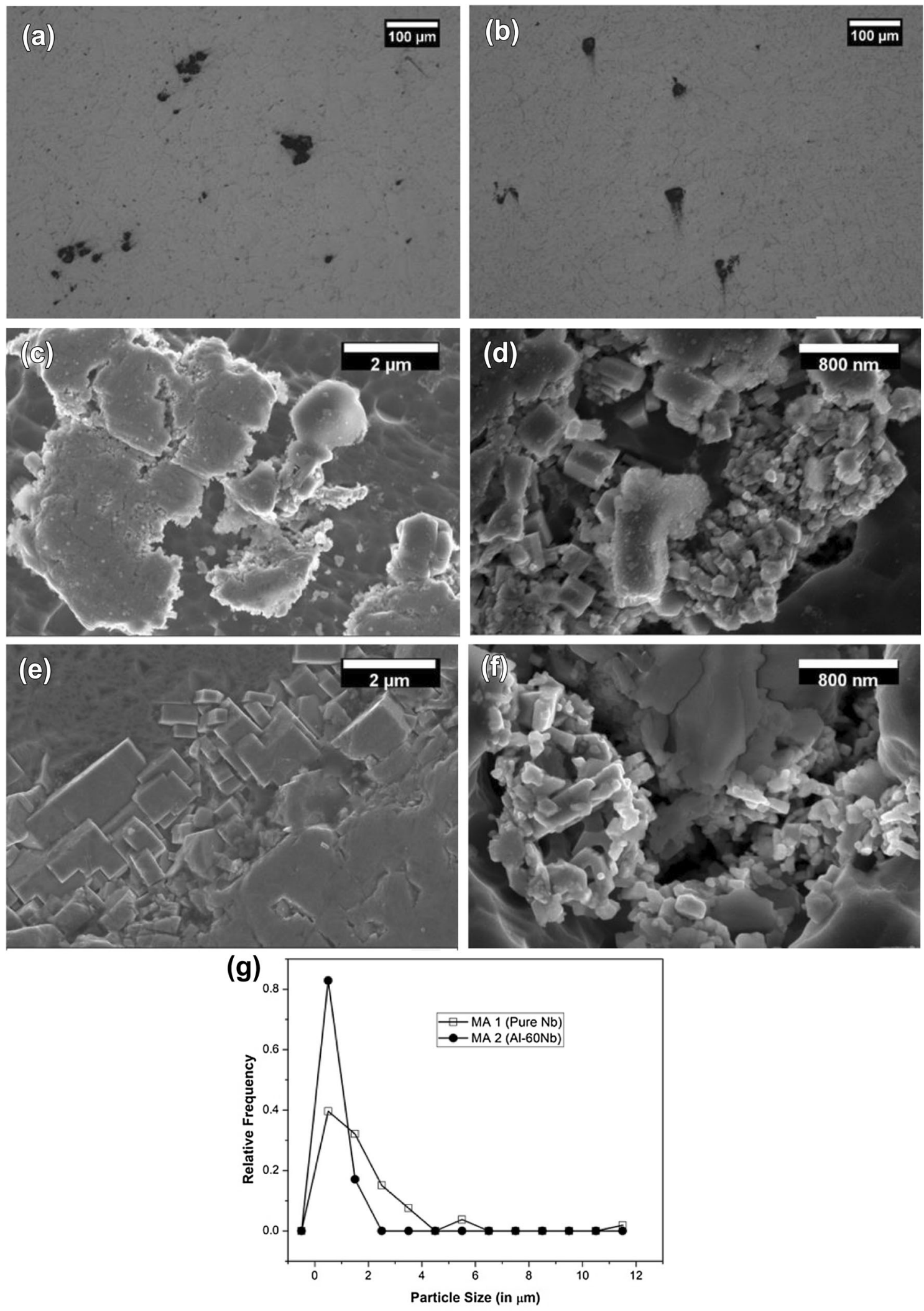

Fig. 4. (a, b) Optical micrographs showing agglomerates of particles formed in Al-5Nb-B distributed throughout the area. SEM images showing

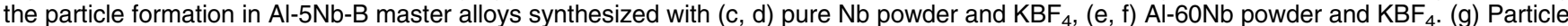
size distribution in MA1 and MA2. 



Fig. 5. FESEM micrograph of master alloys: (a, b) Al-5Nb-2B, (c, d) Al-5Nb-3B. (e) EDS analysis of Al-5Nb-2B master alloy. (f) EDS analysis of Al-5Nb-3B master alloy. (g) Particle size distribution in Al-5Nb-xB $(x=1,2,3)$ master alloys. 




Fig. 6. $\mathrm{XRD}$ analysis of the $\mathrm{Al}-5 \mathrm{Nb}-2 \mathrm{~B}$ master alloy (made with pure $\mathrm{Nb}$ and $\mathrm{KBF}_{4}$ ).

significantly lower than that of pure $\mathrm{Nb}\left(2470^{\circ} \mathrm{C}\right)$ according to the Al-Nb phase diagram. ${ }^{25}$ Hence, it could be possible that the dissolution of $\mathrm{Al}-\mathrm{Nb}$ powders in the aluminum melt is faster than pure $\mathrm{Nb}$. Thus, in the present study where the reaction temperature is $800^{\circ} \mathrm{C}$, reaction kinetics between $\mathrm{Al}-$ $60 \mathrm{Nb}$ and $\mathrm{KBF}_{4}$ would be faster as compared to that between pure $\mathrm{Nb}$ and $\mathrm{KBF}_{4}$. Secpmd, the $\mathrm{Nb}$ is present in the form of $\mathrm{Nb}_{2} \mathrm{Al}$ and $\mathrm{NbAl}_{3}$ in the $\mathrm{Al}$ $60 \mathrm{Nb}$ powder, hence there would be minimum loss of $\mathrm{Nb}$, as their densities are less as compared to elemental $\mathrm{Nb}$ and thus the tendency to settle down would be comparatively less. ${ }^{16}$

\section{Comparative Study of Al-5Nb-xB $(x=1,2,3)$ Master Alloys}

When the concentration of boron was increased from $1 \mathrm{wt} . \%$ to $2 \mathrm{wt} . \%$, the number of particles increased, as expected. Figure 5 shows the microstructure of the two master alloys, Al-5Nb$2 \mathrm{~B}$ and $\mathrm{Al}-5 \mathrm{Nb}-3 \mathrm{~B}$. The particles are very well formed in $\mathrm{Al}-5 \mathrm{Nb}-2 \mathrm{~B}$ (Fig. 5a and b), while the particles in $\mathrm{Al}-5 \mathrm{Nb}-3 \mathrm{~B}$ are relatively coarser and have fewer distinct particles, as seen in Fig. 5c and d.

Figure 5e and $\mathrm{f}$ represents the EDX analyses of particles formed in Al-5Nb-2B and Al-5Nb-3B. The nature of particles formed is similar in both cases, i.e., major elements of the particles being $\mathrm{Al}, \mathrm{Nb}$ and B. With the increase in boron content, the amount of $\mathrm{Nb}$ in the particles has increased. This could be due to an exothermic reaction sustaining for a longer period with the increased amount of $\mathrm{KBF}_{4}$ salt. Further, the increase in B content to 3 wt.\% did not show observable increase in the volume fraction of the particles. This could be due to the high viscosity of the melt observed on the addition of higher amounts of salts, which eventually leads to sticking of the salt-melt mixture to the stirrer and walls of the crucible, which ultimately resulted in poor recovery of $\mathrm{B}$ and a lower fraction of particles formed in the alloy.

Figure 5g shows the size distribution of particles formed in $\mathrm{Al}-5 \mathrm{Nb}-\mathrm{xB}(x=1,2,3)$ master alloys. Most particles in $\mathrm{Al}-5 \mathrm{Nb}-1 \mathrm{~B}$ were found to be in the sub-micron range $(0.1-0.6 \mu \mathrm{m})$, while in $\mathrm{Al}-$ $5 \mathrm{Nb}-2 \mathrm{~B}$, the particle size distribution is much wider, ranging from $0.1 \mu \mathrm{m}$ to $1.8 \mu \mathrm{m}$. The particles in $\mathrm{Al}-5 \mathrm{Nb}-3 \mathrm{~B}$ lie in the same range as $\mathrm{Al}-5 \mathrm{Nb}-$ $2 \mathrm{~B}$. The varied size of the particles in $\mathrm{Al}-5 \mathrm{Nb}-2 \mathrm{~B}$ is preferred for grain refinement. Thus, Al-5Nb-2B was found to be optimum with evidently high recovery of both $\mathrm{Nb}$ and $\mathrm{B}$ and the formation of large numbers of particles.

\section{Characterization of the In Situ Particles Formed in the Master Alloys}

To understand and predict the phases formed in situ in the matrix, XRD analysis of the master alloy was carried out. Figure 6 shows the XRD pattern of the Al-5Nb-2B master alloy. The diffractogram shows peaks of the FCC phase and the HCP phase. The FCC peaks corresponds to aluminum. ${ }^{26}$ To identify the phase with those HCP peaks, powder diffraction files of probable compound, s like $\mathrm{Al}_{3} \mathrm{Nb}$, $\mathrm{NbB}_{2}, \mathrm{Al}_{0.33} \mathrm{Nb}_{0.667} \mathrm{~B}_{2}, \mathrm{AlB}_{2}$, were referred to. In comparisons using standard JCPDS files, the peaks were found to be closest to $\mathrm{Al}_{0.33} \mathrm{Nb}_{0.667} \mathrm{~B}_{2}$ (referred to as aluminum boron niobium), and thus can be assumed to be the same. $\mathrm{Al}_{0.33} \mathrm{Nb}_{0.667} \mathrm{~B}_{2}$ is characterized bya hexagonal lattice structure, with a density of $5.6 \mathrm{~g} / \mathrm{ml}$ and forms a solid solution with $\mathrm{NbB}_{2}{ }^{27}$ As the first two peaks of these two compounds are very close to each other, there might also be a possibility of the presence of some fraction of $\mathrm{NbB}_{2}$ phase.

It is known that phases with a low volume fraction, typically less than $5 \%$, cannot be detected by XRD. Hence, further analysis using SEM-EDS (Fig. 7) was carried out on a few random particles in the $\mathrm{Al}-5 \mathrm{Nb}-2 \mathrm{~B}$ alloy. Figure $7 \mathrm{a}$ and $\mathrm{b}$ are line scans on two particles, representing the distribution of the elements $\mathrm{Al}, \mathrm{Nb}$ and $\mathrm{B}$ in in situ-formed particles. From the scan, it can be observed that all three elements are present in the particles. Figure $7 \mathrm{c}$ and $\mathrm{d}$ are the EDX point analysis on two different particles, showing their approximate constitution. Again, all the three elements, i.e., $\mathrm{Al}, \mathrm{Nb}$ and $\mathrm{B}$, are present. The EDX elemental map of a region of the $\mathrm{Al}-5 \mathrm{Nb}-2 \mathrm{~B}$ alloy is shown in Fig. 7e-i. From the microstructure, it is evident that the particles are distributed along the grain boundaries. Also, it can be inferred that the particles are rich in $\mathrm{Nb}$ and $\mathrm{B}$. The traces of $\mathrm{K}$ indicate the presence of a residue of $\mathrm{KBF}_{4}$ salt. Point EDX analysis on a number of particles indicate the presence of $\mathrm{NbB}_{2}$, $\mathrm{Al}_{0.33} \mathrm{Nb}_{0.667} \mathrm{~B}_{2}, \mathrm{Al}_{3} \mathrm{Nb}$ and $\mathrm{AlB}_{2}$, but, due to their low volume fraction, it could not be detected by XRD. 

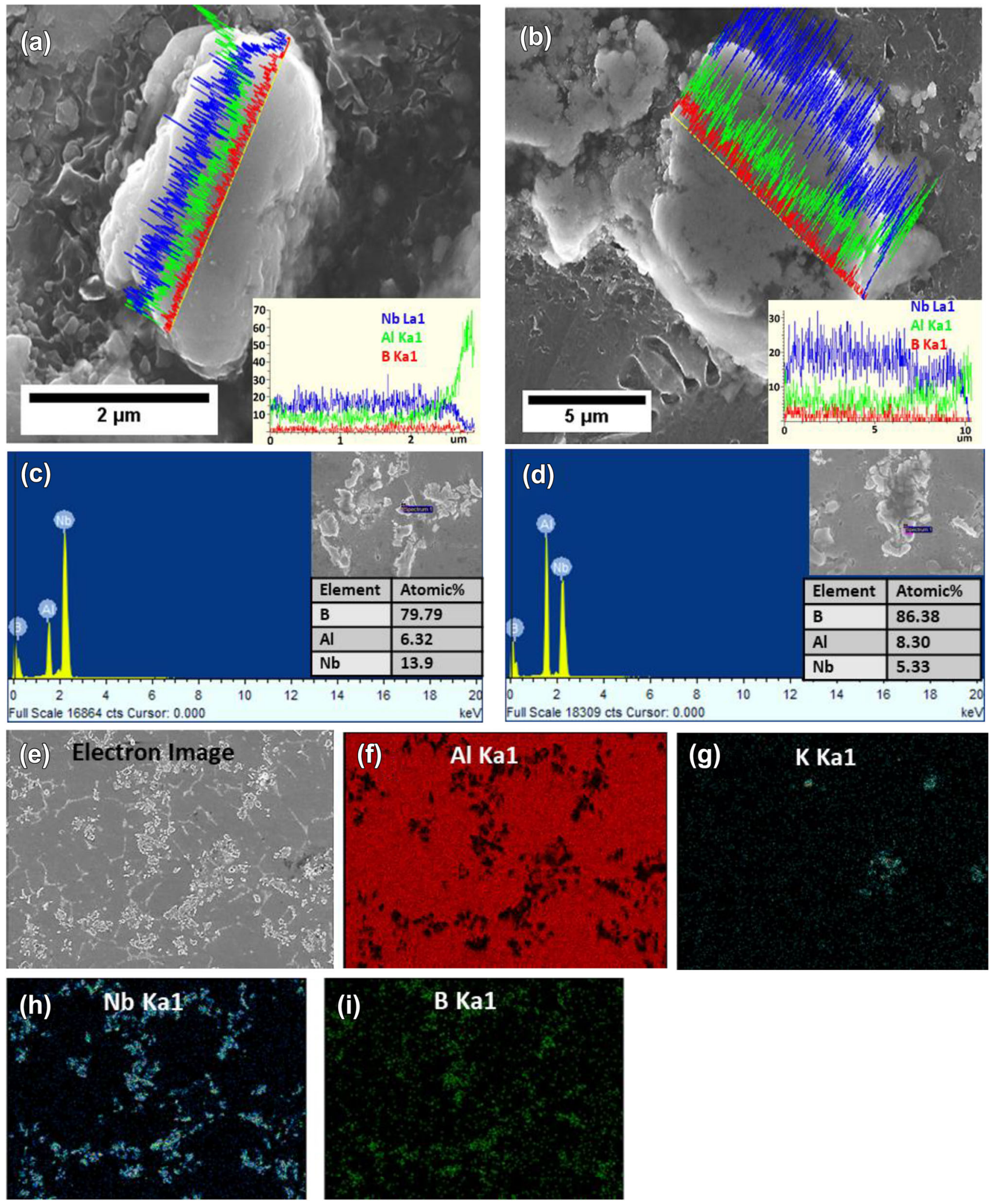

Fig. 7. (a, b) SEM-EDX on intermetallic particles formed in Al-5Nb-2B. (c) Line scan. (d) Point analysis. (e) Electron image of the mapped region. (f) $\mathrm{Al}$ in the region. (g) Potassium in the region. (h) Niobium in the region. (i) Boron in the region. 


\section{CONCLUSION}

$\mathrm{Al}-\mathrm{Nb}-\mathrm{B}$ master alloys with high fractions of weldistributed $\mathrm{Nb}$-B-containing particles were developed by varying the process parameters. A shorter reaction time results in an incomplete salt-metal reaction which is indicated by the presence of unreacted salts and $\mathrm{Nb}$ powder in the solidified master alloy. On the other hand, longer reaction times led to gravity settling of the particles and agglomeration. Thus, the optimum reaction time was found to be $2 \mathrm{~h}$ $15 \mathrm{~min}$ at $800^{\circ} \mathrm{C}$. Also, it was shown that master alloys prepared by the reaction of $\mathrm{Al}-60 \mathrm{Nb}$ powders with $\mathrm{KBF}_{4}$ salt results in the formation of higher volume fractions of particles, as compared to using pure $\mathrm{Nb}$ powder. The experiments also demonstrated that it is not very feasible to synthesize Al-Nb-B alloys with B greater than 2 wt.\% due to the higher viscosity of the melt.

In all the master alloys, agglomerates of particles are well distributed in the matrix. Methods like plastic deformation can reduce the agglomerate/particle size even more, which is beyond the scope of the present work.

\section{OPEN ACCESS}

This article is distributed under the terms of the Creative Commons Attribution 4.0 International License (http://creativecommons.org/licenses/by/4.0/ ), which permits unrestricted use, distribution, and reproduction in any medium, provided you give appropriate credit to the original author(s) and the source, provide a link to the Creative Commons license, and indicate if changes were made.

\section{REFERENCES}

1. B.S. Murty, S.A. Kori, and M. Chakraborty, Int. Mater. Rev. 47, 3 (2002).
2. M.A. Easton, M. Qian, A. Prasad, and D.H. Stjohn, Curr. Opin. Solid State Mater. Sci. 20, 13 (2016).

3. A.L. Greer and T.E. Quested, Philos. Mag. 86, 3665 (2006).

4. A. Cibula, J. Inst. Met. 90, 1 (1951).

5. V. Auradi, S.L. Biradar, S.M. Suresha, and S.A. Kori, Appl. Mech. Mater. 592-594, 494 (2014).

6. L. Arnberg, L. Bäckerud, and H. Klang, Met. Technol. 9, 7 (1982).

7. L. Arnberg, L. Bäckerud, and H. Klang, Met. Technol. 9, 1 (1982).

8. S.A. Kori, B.S. Murty, and M. Chakraborty, Mater. Sci. Technol. 15, 986 (1999).

9. G.P. Jones and J. Pearson, Met. Trans. B 7, 223 (1976).

10. D.G. McCartney, Int. Mater. Rev. 34, 247 (1989).

11. C.R. Chakravorty and M. Chakraborty, Cast Met. 4, 98 (1991).

12. T.W. Clyne, A.M.M. Nazar, M. Prates, and G.J. Davies, Met. Technol. 5, 302 (1978).

13. F. Wang, Z. Liu, D. Qiu, J.A. Taylor, M.A. Easton, and M.X. Zhang, Acta Mater. 61, 360 (2013).

14. F. Wang, D. Qiu, Z.L. Liu, J.A. Taylor, M.A. Easton, and M.X. Zhang, J. Appl. Crystallogr. 47, 770 (2014).

15. T. Wang, H. Fu, Z. Chen, J. Xu, J. Zhu, F. Cao, and T. Li, J. Alloys Compd. 511, 45 (2012).

16. M. Nowak, L. Bolzoni, and N.H. Babu. Mater. Des. 66, 366 (2015).

17. L. Bolzoni, M. Nowak, and N.H. Babu. Mater. Des. 66, 376 (2015).

18. L. Bolzoni and N.H. Babu. JOM 68, 1301 (2016).

19. M. Nowak, L. Bolzoni, and N.H. Babu. J. Alloys Compd. 641, 22 (2015).

20. M. Nowak, W.K. Yeoh, L. Bolzoni, and N.H. Babu. Mater Des. 75, 40 (2015).

21. G.P. Jones and J. Pearson, Metall. Trans. B 7, 223 (1976).

22. M.S. Lee and P. Grieveson, Mater. Sci. Technol. 19, 769 (2003).

23. F. Gazanion, X.G. Chen, and C. Dupuis, Mater. Sci. Forum 396-402, 45 (2002).

24. Y. Birol, J. Alloys Compd. 420, 71 (2006).

25. A. S. M. International, A. S. M. I. A. P. D. Committee, and A. S. M. I. H. Committee, ASM Handbook, vol 3. (ASM International, 1992).

26. E.A. Owen and E.L. Yates, Dublin Philos. Mag. J. Sci. 15, 472 (1933).

27. W. Rieger, H. Nowotny, and F. Benesovsky, Monats Chem 96, 844 (1965). 